\title{
On the Structure and Origin of the Ulodendroid Scar.
}

\author{
BY \\ D. M. S. WATSON, M.Sc., \\ Lecturer on Vertebrate Palacontology in University College, London.
}

With Plate XXXVIII and two Figures in the Text.

SINCE my first discussion of the problem of the origin of the ulodendroid Scar was published, ${ }^{1}$ the description by M. A. Renier of a beautiful specimen, showing a branch still connected with a scar, has placed my primary conclusion beyond dispute. ${ }^{2}$ M. Renier, however, believes that this branch was only attached to the umbilicus instead of the whole area of the scar, a view which seems to me to be negatived by all we know of the structure of lepidodendroid stems and to be inconsistent with the actual structure of well-preserved specimens of Ulodendron.

The only other work of importance which has appeared since is the description by M. P. Bertrand of a Ulodendron with horizontally widened scars, each with a double umbilicus. ${ }^{3}$

M. Renier's theory of the origin of ulodendroid scars is as follows: In the young condition a small branch issues laterally from the trunk, in the way which is perfectly familiar in structural as well as in impression material. Subsequently, by the secondary growth of both branch and trunk, the base of the former is included in the latter and swells rapidly, so as to acquire a conical form, where it is included in the cortex of the trunk. The real external surface of a ulodendroid scar on this theory is the inner aspect of the outer cortex of the conical base of the branch.

Text-fig. I will, I hope, tend to make this view clearer.

The evidence advanced in support of this theory is of two kinds-first, that drawn from impression material examined by its author, and second, supposed evidence drawn from published descriptions of petrified material: this latter appears to me to be evidence founded on misconceptions which could never have arisen had the author examined the original or other suitable structural material of Lepidodendrons with branches issuing laterally.

\footnotetext{
1 Manchester Memoirs, lii, No. 4, I4 pp., 2 plates.

2 Mém. Soc. Géol. Belgique, t. ii, pp. 37-82, Pl. VII-IX.

3 Ann. de la Soc. Géol. du Nord, t. xxxix, I9ıo, pp. 345-6I.
}

[A.nnals of Botany, Vol. XXVIII. No. CXI. July, 1914.] 
The important part of M. Renier's evidence is as follows :

I. M. Renier has found a specimen of a type which, although not common, is still not unusual, in which the quincuncial arrangement of the leaf-traces on the trunk is continued on to the area of the scar on an internal cast. This is held to show that the inner surface of the scar is of the same morphological nature as the inner surface of the outer cortex of the trunk.

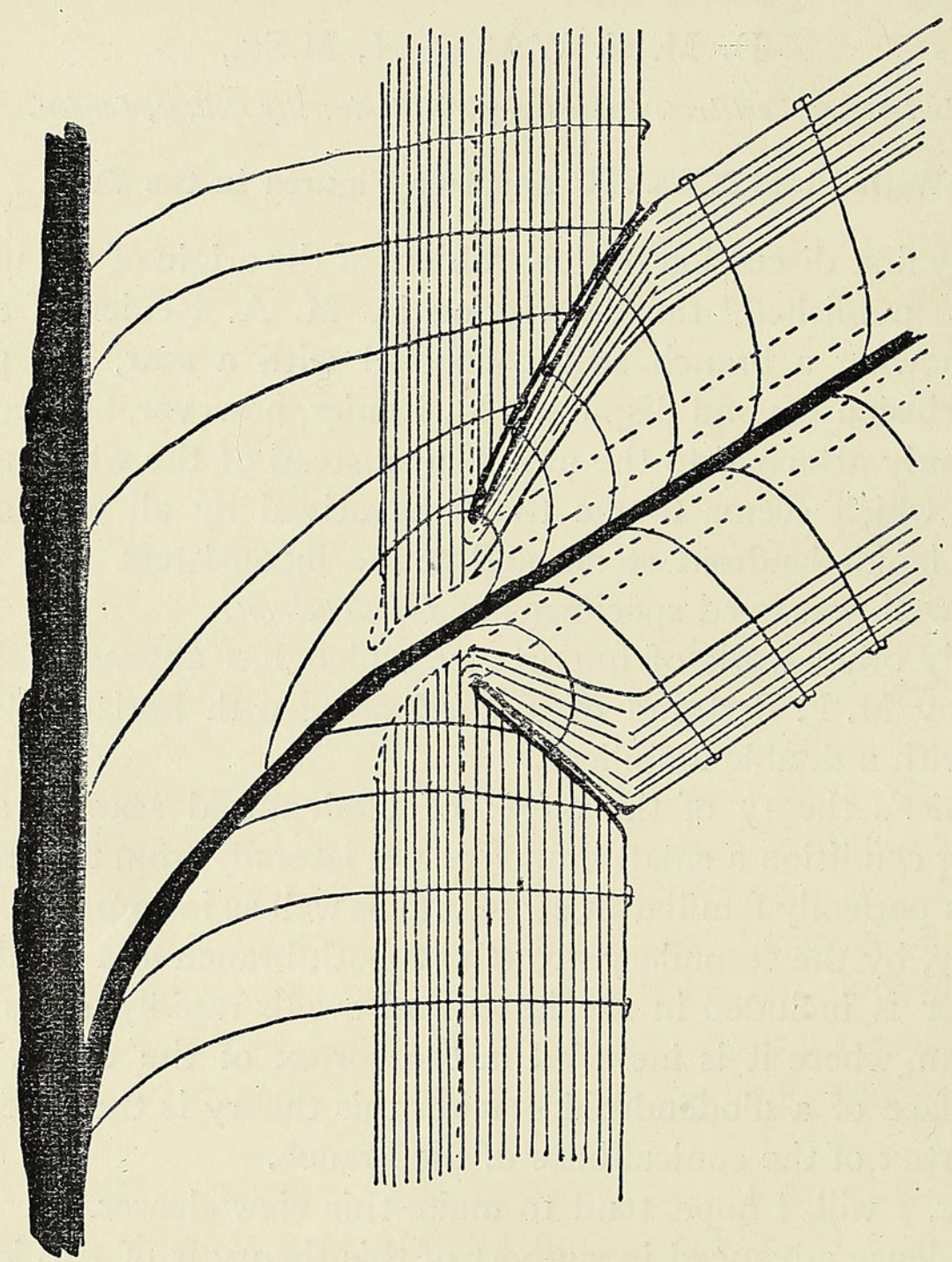

TeXT-FIG. I. A diagram of the base of a ulodendroid branch of Bothrodendron, prepared to illustrate M. A. Renier's theory of the origin of the ulodendroid scar. The dotted lines show the putative original size of the trunk and branch. Wood, black; middle cortex left blank; outer cortex with ruled lining.

2. In a case where both specimen and counterpart of an excellent specimen of Ulodendron are preserved, M. Renier points out that the leaftrace scars on any ulodendroid scar of the specimen which is a cast of the inner side of the outer cortex do not correspond with those of the reverse of the same scar which is an impression of the external surface. M. Renier claims that this non-correspondence can only be explained by assuming that 
the external surface of the scar really represents the internal surface of the conical base of the branch demanded by his theory. This is by far the most important argument advanced by him.

3. M. Renier points out that, in the specimen on which the above observation was made, the leaf-trace sections on a cast of an admittedly subcortical surface of the stem are depressions; the mould of the external surface of the scar also has its leaf-trace sections represented by impressions, and it is reasonable to assume that it is therefore of the same nature as the subcortical cast of the stem.

4. There is usually a raised rim round a ulodendroid scar which can only be a part of the base of the branch.

This is a statement-I believe a fair one-of the whole of the evidence brought forward in support of M. Renier's theory. It will be noticed that none of it is direct; in all cases it depends on the interpretation of certain observed facts.

\section{Discussion OF M. RENIER'S ThEORY.}

M. Renier's theory is open to many objections from a purely general consideration of our knowledge of lepidodendroid stems; some of these are pointed out below.

The structure of the lepidodendroid stem, as it is now known in about twenty-five species of the genera Lepidodendron, Lepidophloios, Sigillaria, and Bothrodendron, is as follows:

I. There is a stele of small size relatively to the diameter of the stem.

2. Surrounding the stele is a broad zone of middle cortex, composed of very soft tissue, usually with intercellular spaces. This tissue decays very readily and is usually lacking in petrified specimens.

3. Surrounding the middle cortex is the outer cortex, composed of hard cells which are proved to be very resistant to decay. This tissue is either uniform throughout or shows a gradual change of character along a radial line.

In the middle of the outer cortex the secondary cortex arises from a cambium which is set up by the division of a cylinder of cells. The secondary cortex seems to resist decay better than any other tissue in the plant: in petrified material, both from the coal balls and such isolated specimens as the types of $L$. Wiinschianum, it is always well preserved, and scraps of it are very common objects in coal-ball sections.

4. Outside the secondary cortex is a thin layer of outer cortex carrying the leaf-bases. In really old specimens this seems to have been commonly shed.

The problem of the 'growth and development' of lepidodendroid stems, is a difficult one, and for our present purpose it is unnecessary to discuss the whole of it; it is, however, necessary to discover what increase in the 
diameter of a lepidodendroid stem may be expected as a result of secondary growth.

It must be pointed out at once that the case is quite incomparable with any that we have an opportunity of examining in living material, as, except for the Lycopods themselves, no living plant has an anatomy of the general type of Lepidodendron, and all the angiospermous trees differ so absolutely in their structure as to give us no help.

It seems certain that when once the wood and outer cortex of a lepidodendroid stem were laid down and matured, their diameter was fixed, as additional tracheides or cells cannot have been introduced.

It must be noticed that this fact, the fixity in dimensions of the primary outer cortex and wood when once matured, implies an enormous mass of living and dividing tissue at the growing point.

I have seen purely primary stems of the order of $15 \mathrm{~cm}$. in diameter, and much larger examples must occur. The idea of a growing point of the order of $20 \mathrm{~cm}$. in diameter is a somewhat remarkable one, but seems to be supported by impressions. Several specimens are known in which a branch whose diameter is of this order ends suddenly, the leaves forming a bunch all over it. A similar occurrence is known in Stigmaria. These cases seem to me to be real growing points, and not to be explicable by any injury.

If we can regard the diameter of the outer cortex as fixed-and, so far as I can see, we must do so-it provides us with a datum by which we can measure the actual increase in diameter of the stem owing to its secondary growth. That we are justified in making this assumption is, I think, rendered very probable by the fact that, whilst, in stems with an appreciable amount of secondary cortex, the cylinder of primary outer cortex which lies outside it and carries the leaf-bases is usually split longitudinally, having been unable to stretch sufficiently to accommodate the growing trunk, the precisely similar ring of primary outer cortex within the periderm is never fissured or in any way injured. This view implies that the secondary growth of the wood has no influence on the diameter of the stem, being allowed for by the crushing up of the middle cortex (the volume of the secondary wood in most cases is so small in comparison with that of the middle cortex as to allow of this taking place).

Accepting the diameter of the primary outer cortex as constant, it is easily seen that the increase in diameter of any lepidodendroid stem is twice the thickness of the secondary cortex. The thickness of the secondary cortex in proportion to the diameter of the stem is always small; in large trunks, in which it is usually greater than in small branches, it may be as much as $9 \mathrm{~cm}$. in a stem of $30 \mathrm{~cm}$. ultimate diameter, as in the Dalmeny tree of L. Wünschianum. This implies an increase of only one-half of the original diameter, an amount which seems to be about the maximum in the very large series of sections I have examined. 
We are now in a position to examine into the possibility of M. Renier's explanation of the ulodendroid scar.

If his view be correct, it should be possible to find a whole series of specimens of Ulodendron in the youngest of which the umbilicus was of nearly the same diameter as the scar, whilst progressively older ones show a gradual increase in the diameter of the scar as compared with the umbilicus. In the whole series of Ulodendrons which I have examined, about two hundred in number, none has an umbilicus more than one quarter of the scar's diameter. This fact alone tells strongly against M. Renier's view.

In the great majority of Ulodendrons, such, for example, as the originals of the figures of this paper, the diameter of the umbilicus is about one-fifth of that of the scar. In Bothrodendron this ratio often drops to one-eighth. On M. Renier's theory, the diameter of the umbilicus represents the original diameter of the branch, which has increased by secondary growth to the diameter of the scar ; that is, the branch must have increased to five or more times its original diameter, but we have seen above that the actual greatest known increase in diameter of lepidodendroid stem observed, in a series which is now very large, is of the order of one-half its original diameter; that is, only one-tenth of the amount required by M. Renier's theory of the ulodendroid scar.

If we suppose, for the sake of argument, that M. Renier's theory is a true one, and that his 'Schema 2' or my Text-fig. I represents the condition of affairs at the bottom of a ulodendroid branch, then it appears that the whole of the stele, inner, and middle cortex of a branch $4 \mathrm{~cm}$. in diameter are only in connexion with the corresponding tissues of the trunk by a neck $5 \mathrm{~mm}$. in diameter, i. e. only one-eighth of the diameter of the branch.

In my last paper on the ulodendroid scar I showed that the diameter of the wood alone, in stems comparable to this in size, is of the order of oneeighth of the diameter of the branch; in other words, the actual wood strand of the branch of M. Renier's 'Schema 2' would only just pass through the hole into the trunk without contraction, and the rest of the stele and the very important middle cortex would be completely cut off, ${ }^{1}$ If, on the other hand, we imagine the stele of the branch to have retained its putative original diameter, then we must suppose that in the mature condition the area of the living and conducting tissues of the base of the branch were suddenly reduced to $\frac{1}{64}$, i. e. $\left(\frac{1}{8}\right)$, of their section further out, which is manifestly improbable.

The foregoing discussion will, I think, have shown the improbability of M. Renier's theory from a purely general standpoint. I now propose to discuss very briefly the case of calamitian branches, which he adduces as analogous to his theory. 
On p. 49 , M. Renier says :

'Les cicatrices ulodendroïdes résultent évidemment de l'accroissement simultané en diamètre de la tige et des rameaux. Ceux-ci acquéraient ainsi une base conique tout comme les rameaux des Calamites.'

The structure of calamitian stems is so extremely different from that of those of Lepidodendron that comparisons of the two always seem to be very unfortunate, and in the present case rest on a complete misconception of the mode of branching of a calamite.

The branching calamitian specimens to which M. Renier obviously refers are those of which the originals of Figs. 3 and 2 of Scott's 'Studies' are examples. ${ }^{1}$ It is true they resemble superficially the D'Arcy Thompson specimen of Ulodendron. ${ }^{2}$ Specimens of this type, however, are invariably only pith casts. Williamson and Scott have shown that mature calamitian branches show no contraction at their base. Dr. Scott has kindly pointed out to me that in very young primary specimens the attachment of branches was really small, but this contraction is obliterated during the secondary growth, and affords no parallel to M. Renier's theory of the ulodendroid scar.

Before discussing M. Renier's specimens, it is necessary to obtain clear ideas of the meaning of the various surfaces which can be seen in impression material of lepidodendroid stems. As M. Renier correctly points out, there are at least three 'assises cellulaires' which may be preserved in impression material.

The innermost of these is commonly the wood, but in a few cases is really the inner cortex, which is usually preserved in petrified stems of Lepidodendron vasculare and Bothrodendron mundum. This zone is not of much importance for our present purpose.

The other two zones may give three distinct types of surface:

(1) On the external surface, the leaf-bases.

(2) The outer surface of the secondary cortex within the leaf-bases.

(3) The inner surface of the outer cortex.

It appears to be probable that in some species old trunks of Lepidodendron shed their leaf-bases, leaving only the secondary cortex exposed. Such specimens have only two types of cortical surface.

It is of interest to try and discover what thickness of coal film may be expected as the result of the conversion of any given thickness of outer cortex into coal. The average specific gravity of coal is about $\mathrm{I} \cdot 25$; that of dry cork 0.3 . This means that, in being converted into coal, cork is reduced to about 0.24 of its volume if we assume, as is of course not the case, that no material is lost in such change. Making a slight allowance for this loss, we find that it is probable that a piece of coal occupies only one-fifth of the

1 D. H. Scott, Studies in Fossil Botany, 2nd ed., vol. i, 1908, pp. I 7 and 18.

2 D. W. Thompson, Notes on Ulodendron and Halonia. Trans. Edin. Geol. Soc., vol. iii, I 880. 
volume of the cork from which it is made; that is, that each centimetre of secondary cortex of a tree-trunk will, on fossilization, be only represented by $0.2 \mathrm{~cm}$. of coal film. To take as an example the thickest secondary cortex of any petrified Lepidodendron represented in the Manchester collections, we find that the secondary cortex of the Dalmeny tree of $L$. Wiinschiamum, which is $4.5 \mathrm{~cm}$. through, would be represented by a coal film $\mathrm{I} \mathrm{cm}$. in thickness. Coal films whose thickness is of this order are often found in connexion with large lepidodendroid trunks.

M. Renier's first specimen is easily explicable on the theory that the branch is attached to the whole area of the scar. The description of it as showing the quincuncial arrangement of the leaf-trace scars of the trunk continued on to the scar is not quite correct. What actually happens is that the multispiral arrangement of the leaf-trace sections on the scar, which are obviously related to the vascular bundle of the branch, is continued on to the ordinary surface of the trunk. This means simply that these latter traces arise from the branch stele after it has parted from that of the trunk. This explanation applies, whichever theory of the scar be held, and the facts are familiar in structural material; cf. Professor Weiss's figures of the 'biserial Halonia'.

The suggestion that it necessarily indicates the similar morphological nature of the inner surface of the scar-tissue and the outer cortex of the trunk is not true, for it is obvious that the intersection of the leaf-traces by a thick abscission tissue, such as is postulated on my theory of the scar, will produce results closely resembling their intersection by the secondary outer cortex.

Although I am not quite convinced of the accuracy of M. Renier's statement that the leaf-trace sections of the inner and outer surfaces of the ulodendroid scars of his second specimen do not correspond, I will accept it for the sake of argument.

I find the thickness of the coal film covering a ulodendroid scar, in the comparatively few (about fifteen) specimens still retaining such a film which I have been able to examine, to be about $\mathrm{I} \mathrm{mm}$.

I have already shown that this must represent a tissue in the plant at least $4 \mathrm{~mm}$., or more probably $5 \mathrm{~mm}$. thick. This would on my theory represent the thickness of the abscission tissue. Except rarely in the lower part of scars, the leaf-traces will never enter this tissue at right angles; they generally do so at a considerable angle. If they do so at $45^{\circ}$, then in passing through the tissue of the scar, which I have shown above to have been in all probability at least $4 \mathrm{~mm}$. in thickness, each will have moved outward a distance of $4 \mathrm{~mm}$., which is ample to explain the differences in position of the sections on the two surfaces of M. Renier's scar.

M. Renier's third piece of evidence is of lesser importance. I shall show later on in this paper that the scars of leaf-traces may be represented 
either by projections or depressions on the outer side of the same tissue in the same specimen.

M. Renier's fourth piece of evidence does not distinguish between the two theories.

It now remains to examine the two structural specimens to which M. Renier appeals in support of his theory; both were described by Professor Weiss, and full series of sections of them are in the Manchester Museum.

The first case is the large stem of Lepidodendron fuliginosum type, which was described by Weiss as the 'biserial Halonia'.' This specimen is regarded by Kidston as a Ulodendron.

It is unfortunately decorticated to such an extent that in the neighbourhood of the lateral branches little or none of the secondary cortex is preserved, and therefore is not in a condition to show that reduplication of the cortex which M. Renier claims to see in it. The inner part of the outer cortex is, however, very thick and well preserved, and is directly continuous from the trunk into the branch. The middle cortex of the trunk is also directly and widely continuous with that of the branch.

Professor Weiss's account is, of course, both accurate and complete, and renders it unnecessary to discuss the stem further.

The other case, the Lepidodendron vasculare figured by Weiss and Lomax, ${ }^{2}$ is slightly different, because the branch, instead of leaving the trunk nearly horizontally, inclines strongly upwards.

Examination of Fig. 3 of this paper, which is a median longitudinal section of a precisely similar specimen, will show that there is no contraction at the base of the branch, which is in organic connexion with the trunk over an area of $5 \mathrm{~cm}$., an amount greatly in excess of the diameter of the umbilicus of any known ulodendroid scar.

The longitudinal section figured in Fig. 3 explains the condition observed in Knorria by Solms-Laubach : ${ }^{3}$

'In the Knorriae... the thinner lateral branch will often impede the further growth in thickness of the main stem, and then the base of the side branchis seen to be embedded on a lateral groove which forms on the stem.

Knorria is a condition which really represents an internal cast of the outer cortex ; the groove referred to by Solms-Laubach is really only a cast of the tongue of outer cortex coming down between the branch and the stem. This tongue is clearly shown in Fig. 3, and equally well in a series of transverse sections of a similar condition on a smaller scale, in Dr. Scott's collection.

M. Renier's suggestion, on p. 50 of his memoir, that Lepidodendron

1 Trans. Linn. Soc. London, 2nd ser., Bot., vol. vi, pp. 21 7-35.

2 F. E. Weiss and J. Lomax, The Stem and Branches of Lepodendron selaginoides. Mem. and Proc. Manchester Lit. and Phil. Soc., vol. xlix, Mem. I 7 , 1905.

${ }^{3}$ Solms-Laubach, Fossil Botany, Oxford, I 89 r, p. 205. 
vasculare may be a Bothrodendron, cannot be upheld, as the work of Hovelacque ${ }^{1}$ has made us well acquainted with the characters of the leafcushions, which are typically lepidodendroid, and project considerably.

It thus appears that the whole of the evidence that M. Renier has furnished in support of his theory is either incorrectly reported or readily explicable on the abscission layer theory of ulodendroid scars.

\section{Description of EXCEPTIONALly Well-PRESERVEd SPeCimens of} ULODENDRON.

I now propose to describe two exceptionally well-preserved specimens of Ulodendron which show that the leaf-traces seen in section on the outer surface of a ulodendroid scar have passed through the tissue of that scar and arisen within the trunk. The proof of this will show that M. Renier's theory, on which the outer surface of the scar is the inner side of the outer cortex of the branch, and should of course receive its leaf-trace bundles from without, is incorrect.

These two specimens belong to the Manchester Museum, and are examples of Ulodendron, sensu strictu; they are preserved as flattened trunks in shale, and are remarkable because they show the outer face of ulodendroid scars as positives on a coal film.

The finer specimen is a piece of trunk, which in its present flattened state measures $19 \mathrm{~cm}$. across, and is $22 \mathrm{~cm}$. long; in this distance it bears three and a half large ulodendroid scars. The whole of one side is still covered with a coal film, the surface of which is preserved with extraordinary perfection, being almost completely free from slickensides.

The stem surface shows the longitudinal cracks which have been luminously explained by Kidston, ${ }^{2}$ as being due to the rupture of the outer layers of the cortex, to accommodate the expanding stem. In the specimen under consideration, these cracks occur also on the scars, showing that considerable secondary growth took place after their formation.

The best-preserved scar is represented by PI. XXXVIII, Fig. 3 .

The general features are well shown in that figure, the sharply markedoff umbilicus, whose gently sloping edges show on the upper half small projections of the same size as the leaf-traces, which can only be the sections of leaf-traces cut during the almost vertical part of their passage, before they turn out into the middle cortex. The whole surface of the umbilicus is covered by a coal film, a fact which is against M. Renier's theory, because on his view it necessarily represents the phloem and middle cortex in addition to the wood of the branch, and these tissues would almost certainly have been defective.

1 Mém. Soc. Linn. de Normandie, xvii.

${ }^{2}$ Ann. and Mag. Nat. Hist., ser, v, vol. xvi, pp. 123, I62, 239. 
The extra-umbilical part of the scar shows excellently the transition from the short, almost circular, sections of the leaf-traces in the lower part, to the elongated scars of the upper part of the ulodendroid disc.

In the lower part, each leaf-trace section is raised on a little cushion, which presents a quite illusory resemblance to a true leaf-base. Examination of the figure will confirm this.

In the upper part each leaf-trace is seen to cut the surface of the scar as an elongated groove, which dips down into the stem towards the umbilicus. Between the point where the leaf-trace has entered the scar surface and the centre, the coal film forms a low ridge, which can only be due to the persistence of the leaf-trace, either within the scar tissue or below it, from the intersection to the umbilicus. This scar therefore affords absolute proof that the outer surface of a ulodendroid scar has received its leaf-trace bundles from within the trunk.

The fact shown in this scar, and still more clearly in the other two perfect scars of the same specimen, that the leaf-trace sections appear as depressions on the upper, and as raised papillae on the lower, part of the same scar, shows that the third line of evidence does not hold in the present example.

The other Ulodendron which I wish to describe is, like the first, a flattened trunk $20 \mathrm{~cm}$. in maximum width, and $66 \mathrm{~cm}$. long, in which distance it bears nine ulodendroid scars on one side, and ten on the other. The coal film has been largely removed from this specimen, leaving a cast of a sub-cortical surface. On this the areas of the scars are faintly marked off in a way not readily intelligible in the light of M. Renier's explanation.

Three ulodendroid scars show a good deal of the coal film. The outer surface of this is well preserved, and confirms the facts observed in the other specimen that I have described. They also show that the leaf-traces seen in section on the outer surface of a ulodendroid scar have sprung from the branch stele whilst still inside the main trunk.

I believe that these two specimens, together with that which I originally described, which is not explained by M. Renier, and seems to be inexplicable on his theory, are sufficient to demonstrate that the branch was attached to the whole area of the scar.

The structure of the scar as seen in the specimens described above, which are probably better preserved than any which have previously been figured, its definiteness, and the smoothness of its surface, can only be explained, if the branch were attached to the whole area of the scar, by calling in the aid of a definite abscission layer comparable to that of leaffall. That we are justified in doing so is shown by the description below of petrified specimens showing such a mechanism. Although it is not certain that these actual examples were Ulodendra, the occurrence of cladopsis in 
a lepidodendroid shows that we are quite justified in supposing that such a process occurred in Ulodendron, where we have strong indirect evidence that such was the case.

\section{Description of an Abscission Layer in Structural Material.}

The two structural specimens in which I am able to demonstrate the presence of a cladopsis mechanism are both members of the genus Lepidophloios, the first being that described by Williamson in his nineteenth memoir as 'Wild's Ulodendron'; though crushed flat, this specimen is very beautifully preserved, and although undoubtedly a Lepidophloios, it bore two opposite rows of lateral branches.

The other specimen is an excellently preserved example of a Lepidophloios agreeing closely with L. Harcourtii; it comes from Shore and is represented by long series of transverse and longitudinal sections in my own collection. The evidence available is not sufficient to determine the arrangement of the lateral branches, which, however, are rather sparsely and apparently irregularly scattered, possibly somewhat as in Lindley and Hutton's Halonia tortuosa.

These specimens agree exactly in the structure of the abscission layer which cuts off their lateral branches, but this layer is somewhat younger in 'Wild's Ulodendron' than in the other case.

In a transverse section of the specimen of L. Harcourtii, No. 203, part of which is shown in Pl. XXXVIII, Fig. 2, a lateral branch, $14 \mathrm{~mm}$. in diameter, is shown in accurate median longitudinal section. Of this branch only a short stump $5 \mathrm{~mm}$. long is preserved, but this shows in excellent preservation the outer, middle, and inner cortices and the stele. In the section figured, the stele is shown in median section, passing inwards till it reaches the level of the periderm of the stem; it then, as is shown by other sections, turns sharply downwards, and passes in gradually until it reaches the stele of the main stem.

The leaf-base-bearing tissue of the stem is directly continuous with that of the branch, and from the periderm of the stem a little upstanding rim of periderm is formed in the base of the branch; this is quite normal and surrounds the branch in the usual position in the primary outer cortex.

Inside the outer cortex the thick and well-preserved middle cortex occurs. It has the ordinary loose tissue full of air spaces, but is not composed of long hyphae-like filaments, as is that of L. fuliginosum. Inside this are the inner cortex and stele, which show no unusual features. Such in brief is the structure of the branch. The evidence of other specimens, such as Weiss's biserial Halonia, shows that in the young stem all these tissues of the branch are in direct connexion with the corresponding tissues of the stem. 
In the present case, however, the whole base of the branch is cut off by a thick layer of secondary tissue. This layer is nearly flat, but possesses a depression, forming a small conical pit on its outer surface round the stele of the branch.

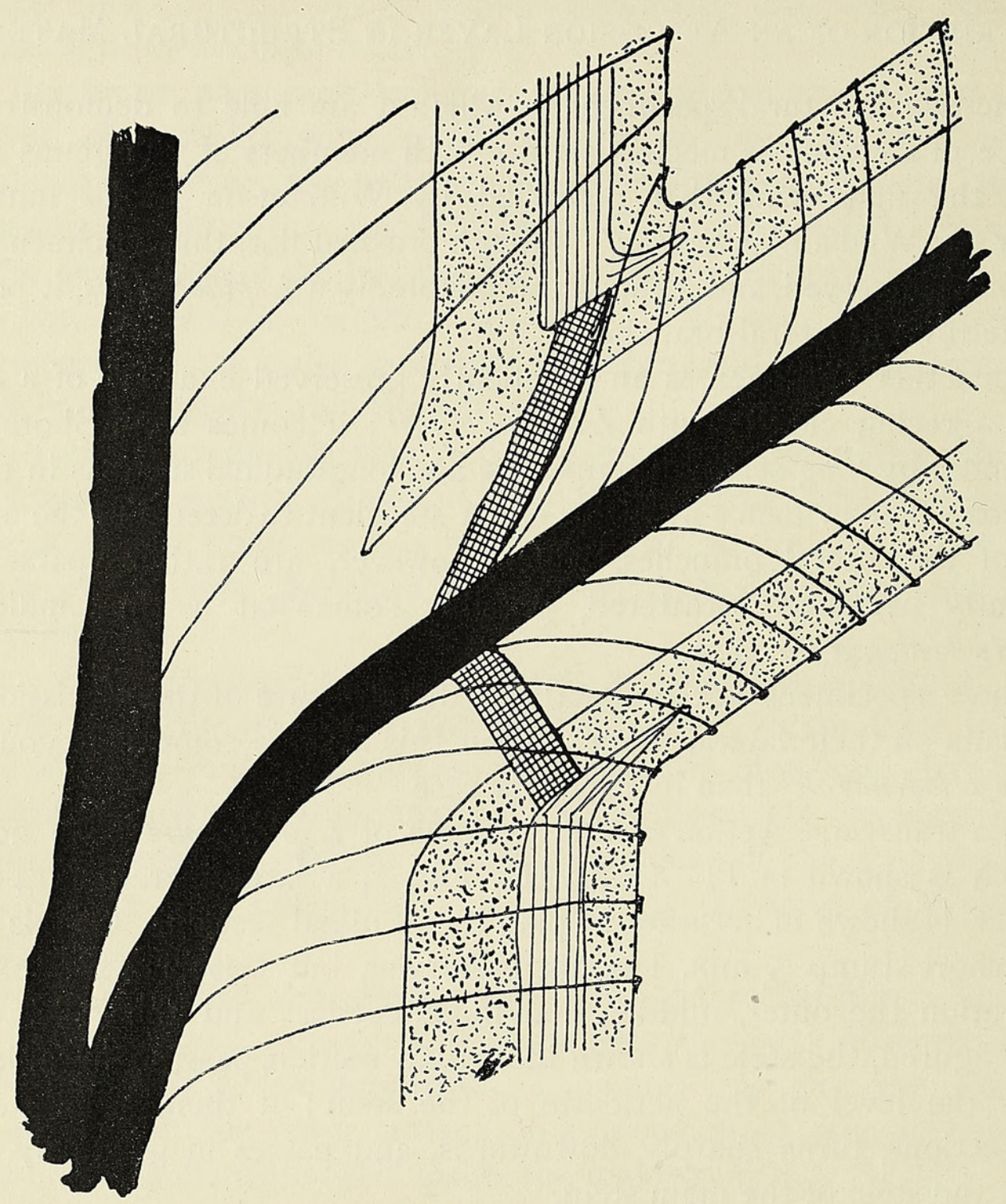

TEXT-FIG. 2. A diagram of the base of a ulodendroid brancb, to illustrate the abscission-layer theory of its origin. Wood, black; middle cortex left blank; primary outer cortex stippled; secondary cortex ruled; abscission layer cross-hatched.

This secondary tissue has obviously been formed by a cambium which has arisen in the living tissues of the base of the branch-in the inner layers of the outer cortex, middle cortex, and stele, without any distinction; it cuts right across everything and must have rapidly led to the death of the branch.

In both cases, but particularly in the case under discussion, this layer of secondary tissue becomes continuous with the general periderm of the stem, but it joins this only where the periderm of the branch turns out from it, so as to leave the latter as a low rim round the branch scar. 
Finally, in the specimen under discussion, another cambium arising in the deeper layers of the outer cortex has developed a considerable amount of secondary tissue within the main periderm. This cambium appears to have spread to the middle cortex of the base of the branch, where a thick layer of secondary tissue, indistinguishable from that of the main stem, has been formed. In fact, the final result is that the separative tissue across the base of the branch has completely assimilated itself to the secondary cortex of the main stem. This fact explains some of the appearances by M. Renier in impression material of Ulodendron.

That the tissue I have just described is really an abscission layer is, I think, certain from its close resemblance to the ordinary mechanism of leaf-fall of dicotyledonous trees, and to the cladopsis of Agathis.

It thus seems to be almost certain that the typical ulodendroid scar is a thickened abscission layer at the base of a laterally issuing branch.

\section{General Discussion of Ulodendron.}

It will be of interest to examine Ulodendron, and also Halonia, in the light of this new knowledge.

As Dr. Kidston pointed out many years ago, three types of the ulodendroid condition occur: ${ }^{1}$

I. With the scars oval, well separated, and with a central umbilicus.

2. With the scars oval, well separated, and with an eccentric umbilicus.

3. With the scars circular, close together, and with a central umbilicus.

Specimens at Manchester suggest that there is still a fourth type. umbilicus.

4. With the scars circular, well separated, and with a central

It is useful to consider the meaning of the difference between these types. The difference in the shape of the scar is easily seen to be entirely dependent on the direction of the branch; circular scars can only be produced when the branch issues horizontally and at right angles to the surface of the trunk.

Oval scars will be produced when the branch does not leave the surface at right angles, but inclines upward. Its section by the outer surface will then be nearly an ellipse.

The position of the umbilicus is of more interest; it is certain that in those cases where the scars are oval and the umbilicus eccentric, the surface of the scar was, during life, a deep conical pit. Casts of this pit are very common, and that it was present is always obvious even from the examination of crushed specimens. 
The other type of oval scar, with a central umbilicus, can only be produced when the outer surface of the scar was, in life, nearly flat; this is readily obvious from the inspection of hypothetical median longitudinal sections.

It thus appears that ulodendroid scars may be flat or nearly so.

It is almost certain that the scars of Ulodendron proper, that is, the type with contiguous circular scars and a central umbilicus, were also usually flat, or at most only slightly depressed.

The proof of this statement is as follows:

I. There is in the Manchester Museum a portion of a round stem of Ulodendron preserved in ironstone, which is apparently uncrushed, and in which the scars are essentially flat.

2. If the scar had been at all deeply conical, the tissue composing it would have been puckered when it was crushed flat. Such well-preserved external surfaces as the originals of Pl. XXXVIII, Figs. I and 2, never show any sign of such puckering.

At the same time, a well-preserved specimen from Low Moor, in the Bradford Museum, which is preserved in ironstone, and hence only slightly crushed, does show slightly depressed areas. The only specimen which has ever been figured as showing the scars as deep conical pits is that described by Carruthers. ${ }^{1}$ This specimen, which I have never seen, has probably been misinterpreted. It is possible that it was so preserved that the leaftrace bundles going to the scar were interpreted as the scar surface itself; at any rate it seems certain that, in the vast majority of cases, the scars of Ulodendron, sensu strictu, were flat, or at most but slightly depressed.

The question of the attribution of ulodendroid trunks to different genera presents some difficulties.

It is generally conceded by all palaeobotanists that those specimens with oval, well-separated scars and an eccentric umbilicus belong to Bothrodendron.

Those specimens which have the scars oval, well separated, and with a central umbilicus, occur in the Lower Carboniferous as well as in the Coal Measures, where they appear to be very rare.

In all cases that I have seen, or found recorded in the literature, individuals of this type have their leaf-bases higher than they are broad, and apparently of the Lepidodendron type. Those from the Lower Carboniferous of Scotland were referred by Dr. Kidston in 1885 to Lepidodendron veltheimianum; the very few Coal Measure specimens I have seen are referable to Kidston's L. Landsburgii.

These specimens have leaf cushions often well preserved, and strikingly like those of Lepidodendron; but in those cases that I have seen the leaf-scar is never visible, and the leaves seem to have remained attached to the stem 
for a very long period, and not to have been shed as in an ordinary Lepidodendron, a fact which may be held to justify the removal of the species from Lepidodendron proper.

The type with contiguous circular scars was referred by Dr. Kidston to Sigillaria. Here again, no specimen showing well-preserved leaf-scars has ever been figured, although specimens showing the cushions perfectly preserved are not uncommon. As in the former case, this fact raises a strong suspicion that the leaves were never shed by the intervention of an abscission layer. The specimens I have seen, although not conclusive, suggest that the leaf was only attached to quite a small area at the top of the leaf-cushion, instead of to a very large part of it as in Sigillaria.

On the whole it is perhaps best to keep the genus Ulodendron, and to include in it both types, that with long leaf-bases, and that with short, square cushions. At the same time it must be understood that the difference between these and Lepidodendron is very small, probably consisting solely in the longer retention of the leaves.

This long retention of the leaves is probably due to the fact that, when the whole branch was shed, it was unnecessary to make special arrangements for shedding each individual leaf.

The fact that the specimen of Lepidodendron fuliginosum type described by Professor Weiss as a biserial Halonia has been identified by Kidston as Sigillaria discophora, an identification with which I agree, shows that Ulodendron, in its structure, approaches much more nearly to the Lepidodendron type than it does to any form of Sigillaria.

\section{General Discussion of Halonia.}

It is of interest to consider the halonial branch in the light of our knowledge of Ulodendron.

As has been recognized for many years, the two forms resemble one another in being lepidodendroid stems which have borne series of lateral appendages. Much confusion between the two types exists in the literature, but when well preserved they are readily distinguished. As Dr. Kidston pointed out many years ago in a classical paper, Ulodendron has invariably its scars in two opposite rows, whilst in Halonia they are typically in a series of spirals running round the stem. Another difference which seems to me quite typical is that Halonia is very often found branching, forming in fact the ultimate branches of the tree, whilst only one branching specimen of Ulodendron seems to be known, and the stems always seem to be the main trunks, a conclusion which is proved in the case of the two vertical specimens in the Manchester Museum.

Dr. Kidston has shown that all satisfactory specimens of Halonia belong to the genus Lepidophloios. 
In a typical specimen of Halonia, preserved so as to retain the leafbases, such for example as the specimen figured by Williamson in his nineteenth memoir, P1. VI, Fig. $25 \mathrm{~A}$, as a multiseriate Ulodendron, the halonial 'tubercles' are seen in the form of large, slightly depressed areas, recalling the scars of Ulodendron. They are, however, of very different structure; each scar is divisible into two concentric areas, of which the inner is usually smooth and shallowly concave, whilst the outer is divided into irregular segments by more or less radial lines. Examination of the outer area in any well-preserved specimen will show that it is solely impressed on the long leaf-bases of the stem, having been formed by the pressure of the equally long leaf-bases of the branch. In the case of any of the scars in Williamson's specimen, the second and third from the top in the centre row being the best preserved, the inner area which is not leaf-base is $0.5 \mathrm{~cm}$. in diameter, whilst the whole area is $1.5 \mathrm{~cm}$. across. These sections should be the diameters of the outer cortex of the branch and of the whole branch. A section of Lepidophloios macrophyllum (Q.418, Cash Coll., Manchester Museum), I.5 cm. in greatest diameter, has an outer cortex only $0.5 \mathrm{~cm}$. in diameter, and so agrees exactly with the condition which must have occurred in the original of Williamson's figure. The fact that the greater part of the halonial area is made of the leaf-bases shows that this type can only occur in Lepidophloios, which genus alone has leafbases long enough to form the outer part of the area. What is in essence this explanation has already been given by Dr. Kidston.

One very interesting specimen of Halonia from the famous quarry 'Peel Delph', which is in the Manchester Museum, is preserved as a very fine cast in sandstone of the interior of the outer cortex. This cast is still attached to the matrix, and shows that the very prominent tubercles, which occur in all Halonias preserved as Knorrias, do not touch the mould of the outer surface of the stem by nearly I $\mathrm{mm}$. This space must represent some tissue in the plant which had not decayed at the time it was buried, and as it cuts completely across the base of the branch, this structure can only be an abscission layer, similar to that which I have demonstrated in structural material. The halonial tubercles themselves obviously represent the casts of the holes in the outer cortex left by the decay of the middle cortex of the base of the branch.

The evidence that Dr. Kidston brought forward in the case of the halonial branches of Lepidophloios scoticus, although not quite conclusive, seems to render it very probable that the appendages of the halonial tubercles of that type were cones borne on the end of long peduncles.

The fact that the possible increase in diameter of lepidodendroid stems by secondary growth is very small shows that in such cases as that figured by Williamson (nineteenth memoir, Pl. VIII, Fig. 23), the lateral appendages of halonial tubercles must have been of very large size-at least $2 \mathrm{~cm}$. in 
diameter in the case cited; this is considerably larger than the axis of any known lepidodendroid cone, and hence probably of any cone peduncle, which suggests that in some cases at any rate the lateral branches were not cones.

The above brief discussion shows that halonial tubercles bore lateral branches (which may in some cases have been the peduncles of cones), which were shed by the intervention of an abscission layer, just as were the branches borne by ulodendroid scars, and that the two cases differ in the arrangement of the branches, in their position on the plant, and in the structure of the scars owing to the presence in Halonia of an aureola of leaf-bases pressed down by those of the branch, a condition only possible in Lepidophloios.

\section{Summary of New and Disputed Facts and Conclusions.}

I. In Lepidodendroids, small branches issuing laterally were sometimes shed by an abscission layer, developed from a cambium which forms across the base of the branch in all its living tissues, except that part of the primary outer cortex which lies outside the secondary cortex. This abscission layer becomes connected with the secondary cortex of the main stem, and in old age entirely takes on the structure of the latter.

2. The ulodendroid scar is such an abscission layer cutting off a branch which was formerly attached to its whole area.

3. Halonia is essentially similar to Ulodendron, in that it represents a stem from which lateral branches have been cut off by an abscission layer.

4. The most practical distinction between Halonia and Ulodendron lies in the arrangement of the branches, but the scars themselves are quite different when well preserved.

5. The well-preserved halonial scar is divisible into two areas, of which the inner represents the abscission layer, whilst the outer results from the pressure of the long leaf-bases of the branch on those of the stem; consequently the halonial condition can only occur in Lepidophloios.

6. In some cases, at any rate, the lateral branch of Halonia was not the peduncle of a cone.

7. No specimen of Ulodendron showing a well-preserved leaf-scar has ever been described, except in that type with oval scars and an eccentric umbilicus, which belongs to Bothrodendron.

8. Consequently it is best to retain the generic name Ulodendron, as is done by most continental authorities.

9. The reason why the leaf-scars are not found is that when whole branches were shed it was unnecessary to shed the individual leaves. 
I0. The increase in diameter of lepidodendroid stems, owing to secondary growth, is very slight.

II. The growing points of Lepidodendron must have been of very great size.

I wish to express my thanks to Professor Sir T. H. Holland, in whose department in Manchester this paper was written some time ago, and to Professor F. E. Weiss and Dr. D. H. Scott, for advice and criticism in relation to it.

\section{EXPLANATION OF PLATE XXXVIII.}

Illustrating Mr. Watson's paper on the Structure and Origin of the Ulodendroid Scar.

Fig. I. 'Wild's Ulodendron.' Transverse section of a large stem giving off a lateral branch, the stele of which is just cut tangentially at the extreme top of the photograph. The lighter coloured tissue surrounding this stele and the corresponding light area in the main stem are the middle cortex. The separative tissue is clearly seen cutting across this, and at the extreme right it comes in contact with the periderm of the main stem. Specimen in the Manchester Museum.

Fig. 2. Transverse section of a stem of Lepidophloios Harcourtii, showing a lateral branch in median longitudinal section. This is fully described in the text, p. 49I. A 20, D. M. S. Watson Collection.

Fig. 3. Ulodendron majus. Photograph of an exceptionally well-preserved scar; everything visible is on a coal film and hence represents the real exterior surface. Further described at p. 489 . X. I., Manchester Museum.

Fig. 4. Ulodendron. Photograph of a scar still retaining some of its coal film. Further described at p. 490. X. I., Manchester Museum. 
Anrals of Botany,

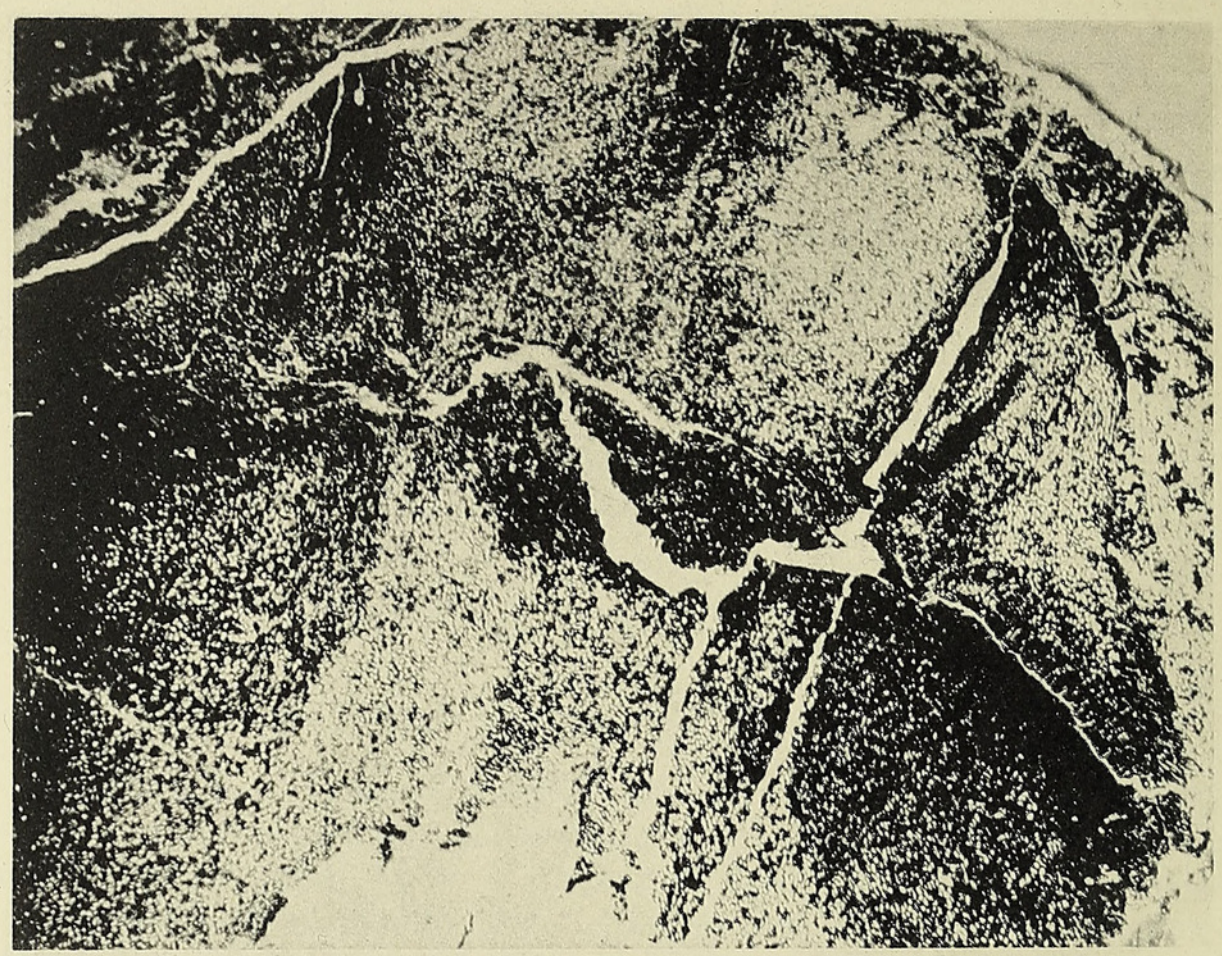

1 .

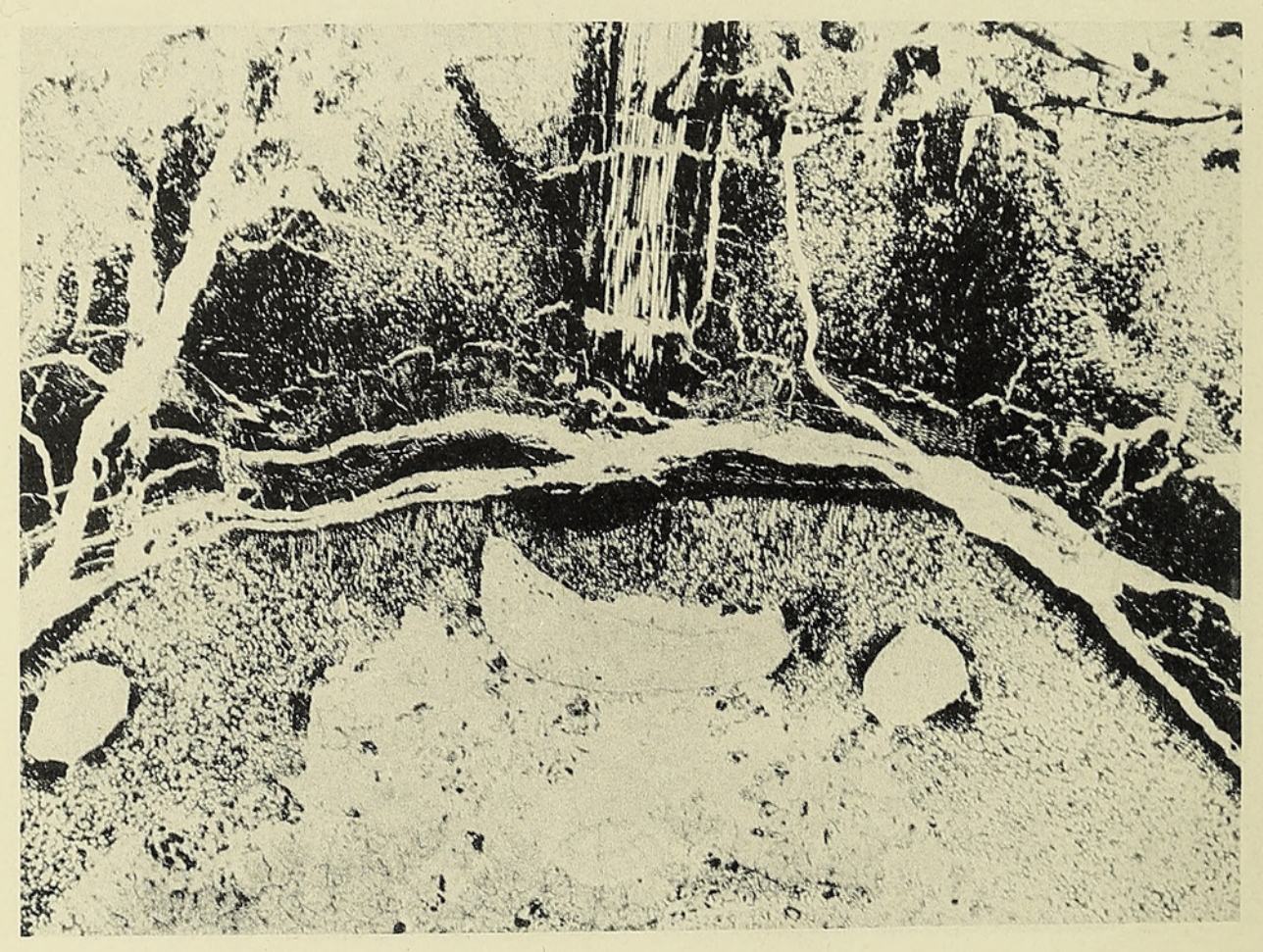

2 .

WATSON ULODENDROID SCAR. 


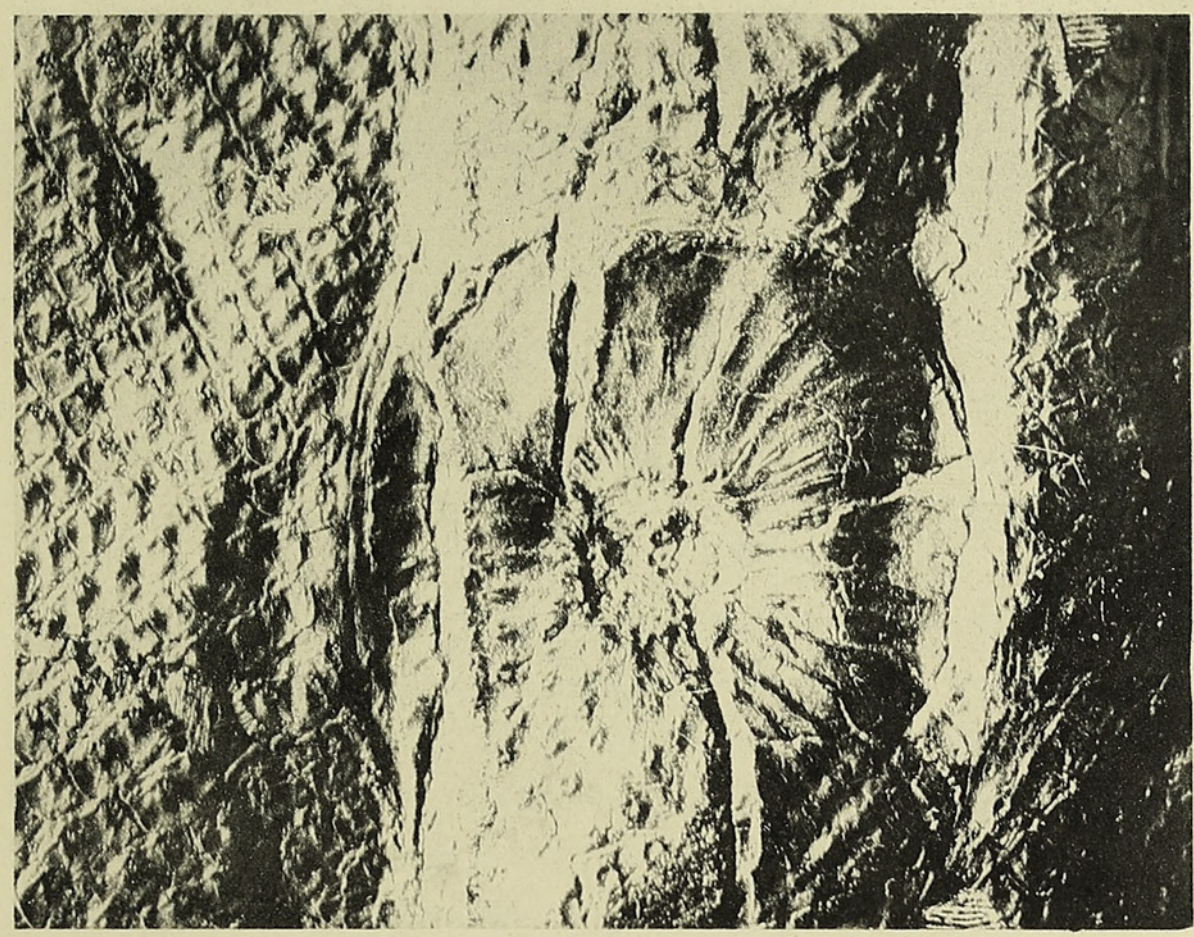

3.

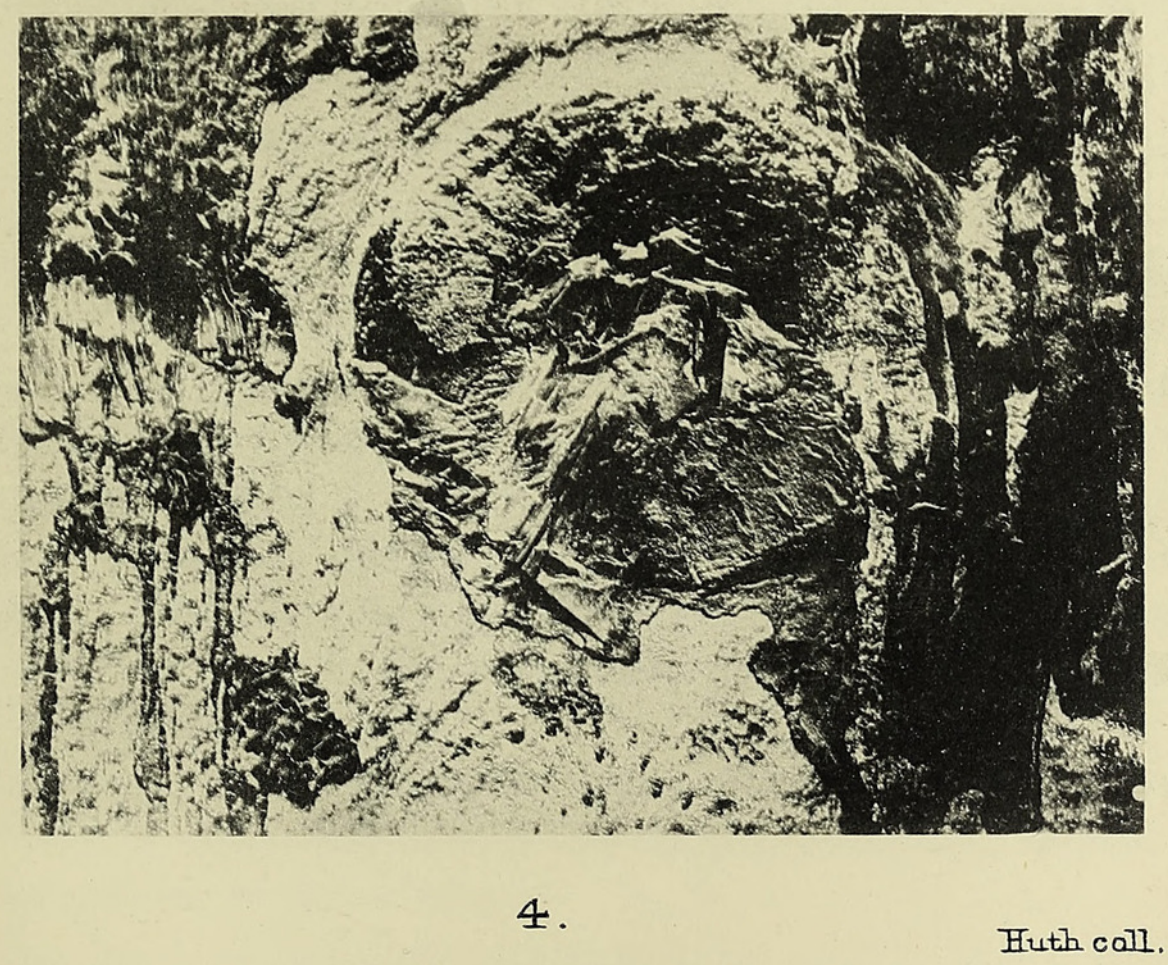



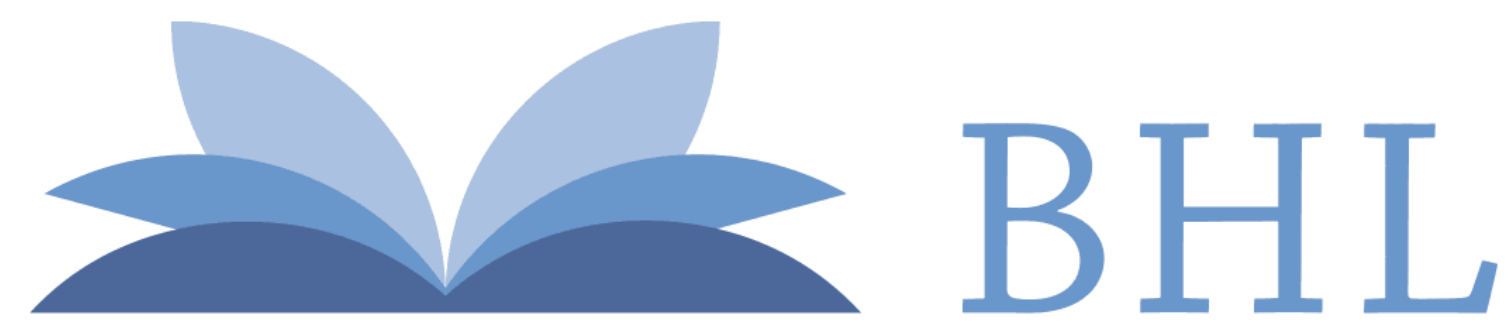

\section{Biodiversity Heritage Library}

Watson, David Meredith

Seares,

ๆ

阝

. 1914. "On the structure and origin of the ulodendroid scar." Annals of botany 28, 481-498. https://doi.org/10.1093/oxfordjournals.aob.a089516.

View This Item Online: https://www.biodiversitylibrary.org/item/236856

DOI: https://doi.org/10.1093/oxfordjournals.aob.a089516

Permalink: https://www.biodiversitylibrary.org/partpdf/320034

\section{Holding Institution}

Smithsonian Libraries

\section{Sponsored by}

Biodiversity Heritage Library

\section{Copyright \& Reuse}

Copyright Status: Not in copyright. The BHL knows of no copyright restrictions on this item.

This document was created from content at the Biodiversity Heritage Library, the world's largest open access digital library for biodiversity literature and archives. Visit BHL at https://www.biodiversitylibrary.org. 